\title{
RELATIVE REACTIVITIES OF ALKENES TOWARD THE DIPHENYLMETHYL CATION
}

Herbert Mayr* and Rudolf Pock

Institut für Organische Chemie der Universität Erlangen-Nürnberg

Henkestr. 42, D-8520 Erlangen

Summary: The relative reactivities of alkyl and phenyl subsituted alkenes toward diphenylmethyl chioride/ $\mathrm{ZnCl}_{2} / \mathrm{Et}_{2} \mathrm{O}$ in dichloromethane at $-78^{\circ} \mathrm{C}$ have been determined by competition experiments. The transition state structure is discussed.

Cationic copolymerisation parameters, which can only be obtained with difficulty, are presently the major source for relative alkene reactivities toward carbenium ions. ${ }^{1}$ only few other approaches to that problem have been untertaken, ${ }^{2,3}$ since carbenium ion additions to alkenes often give complex mixtures of products, including polymers. We have reported recently that Lewis acid catalysed addition reactions of alkyl halides to alkenes may yield 1:1 addition products selectively, if the reactants AX dissociate faster than the products

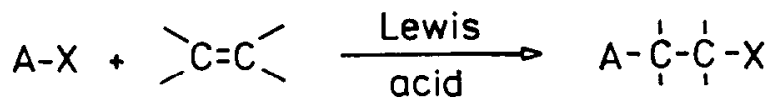

A-C-C-X. ${ }^{4}$ Alkyl halides with high $S_{N} 1$ reactivity are therefore suited to give $1: 1$ adducts with a variety of alkenes with different nucleophilicity. ${ }^{5}$ In this work we selected the zinc chloride catalysed additions of benzhydryl chloride (1) to determine relative alkene reactivities toward the diphenylmethyl cation.

PRODUCTS. At $-78^{\circ} \mathrm{C}$ benzhydryl chloride $(\underline{\underline{1}})$ reacts with $\underline{2 a}-\underline{\underline{a}} \underline{\underline{1}} \underline{\underline{l}}$ in presence of the homogeneous catalyst system $\mathrm{ZnCl}_{2}-\mathrm{Et}_{2} \mathrm{O}$ in dichloromethane ${ }^{6}$ to give high yields of 1:1-addition products. On a preparative scale more than $80 \%$ of purc $1: 1$ products are usually accessible. ${ }^{7}$ The unsymmetrical alkenes of Table 1 undergo regioselective addition reactions in Markownikoff sense. Cis- and trans-2-butene react stereospecifically to give diastereomeric addition products of unknown configuration as well as traces of 1,1-diphenyl-2-methyl-1-butene. Normal addition products are also obtained from cis and trans-1-phenylpropene (2k : stereospecific; 21: nonspecific), while these reactions have been reported to yield indanes at room temperature. $^{2}$ Under our conditions only $\underline{\underline{1}}$ and $\underline{2 h}$ give a cyclised product $(1,1,2,2$-tetramethyl-3phenylindane) besides the normal 1 inear adduct. Norbornene reacts with Wagner-Meerwe in rearrangement to yield syn-7-benzhydryl-exo-2-chloro-norbornane exclusively.

METHOD. Competition experiments were carried out by adding 1 to a homogeneous solution of $\mathrm{ZnCl}_{2}-\mathrm{Et}_{2} \mathrm{O}$ and a mixture of two alkenes in $\mathrm{CH}_{2} \mathrm{Cl}_{2}$ at $-78^{\circ} \mathrm{C} . \overline{8}$ After completion of the 


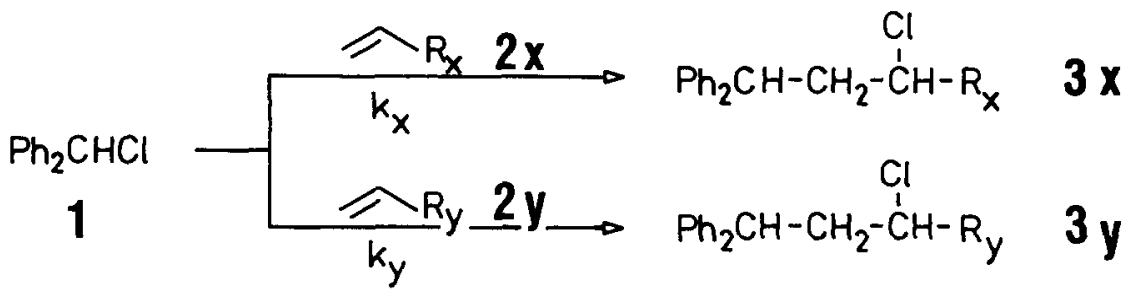

reaction, the catalyst was extracted with aqueous ammonia, and the product ratio ( $R$ in eq. 1 ) was determined by HPLC. ${ }^{9}$ Since the experiments were not carried out under pseudo first order conditions, ${ }^{8}$ eq. 1 was used to evaluate relative reactivities. 10

$$
k_{x} / k_{y}=\log \left(1-\frac{[1]_{0} R}{[2 x]_{0}(1+R)}\right) / \log \left(1-\frac{[1]_{0}}{[2 y]_{0}(1+R)}\right) ; \text { with } R=\frac{[3 x]}{[3 y]} \text {; }
$$

Each rate ratio listed in Scheme 1 was determined 2-5 times with variable relative alkene concentrations. Deviations of less than $\pm 10 \%$ were obtained, when the $\underline{2} \underline{\underline{x}} / \underline{\underline{2}} \underline{\underline{y}}$ ratio was varied within a factor of 10 . Reaction time did not influence the product ratio, indicating irreversibility of the addition reactions. When $\mathrm{ZnCl}_{2} / \mathrm{Et}_{2} \mathrm{O}$ was replaced by $\mathrm{BCl}_{3}$, a rate ratio similar to that in Scheme 1 was obtained for $2 \underset{=}{=} \stackrel{2}{=} \underset{1}{=}(21.6)$. This finding suggests that the relative reactivities reported in this paper may not be restricted to one specific catalyst system.

The data in Scheme 1 were used to calculate relative rate constants (Table 1 ). Some $k_{\text {re } 1}$ values can be obtained in different ways since some of the data in Scheme 1 are redundant. In these cases deviations up to $20 \%$ (average $10 \%$ ) were obtained, indicating the precision of our data.

\section{$\begin{array}{llllllllllll}2 a & 2 b & 2 c & 2 \mathrm{i} & 2 \mathrm{l} & 2 \mathrm{j} & 2 \mathrm{~d} & 2 \mathrm{f} & 2 \mathrm{e} & 2 \mathrm{k} & 2 \mathrm{~h} & 2 \mathrm{~g}\end{array}$}

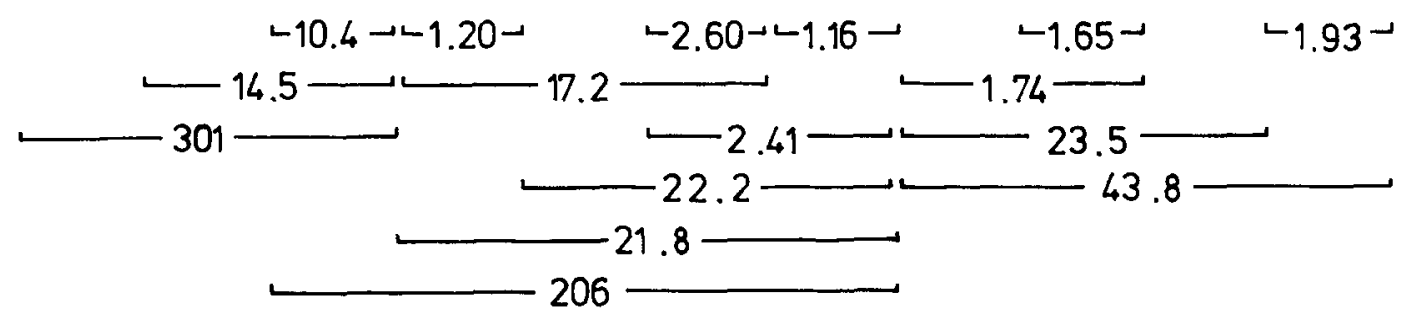

Scheme 1: Relative Alkene Reactivities toward $\mathrm{Ph}_{2} \mathrm{CHCl} / \mathrm{ZnCl}_{2}$ in $\mathrm{Et}_{2} \mathrm{O} / \mathrm{CH}_{2} \mathrm{Cl}_{2}$ at $-78^{\circ} \mathrm{C}$

DISCUSSION. The relative olefin reactivities toward dibhenylcarbenium ion (Table 1) reflect roughly the stabilities of the carbenium ions formed during addition. $2 \underline{a}-\underline{2} \underline{\underline{2}} \underline{\underline{c}}$ yield secondary carbenium ions and are 3-5 powers of ten less reactive than $2 \mathrm{~d}-\underline{\underline{d}} \underline{\underline{2}}$, which give tertiary

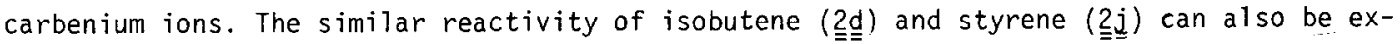
plained by the relative carbenium ion stabilities derived from solvolysis data, which show that phenyl exerts a similar stabilization as two methyl groups. ${ }^{18}$ As in other addition reactions, ${ }^{19}$ norbornene $(2 \underset{1}{j})$ is found to be more reactive than ordinary 1,2-dialkylated ethylenes $(\underline{\underline{2}} \underline{\underline{b}}, \underline{\underline{c}})$. 
Table 1. Reactivities of Alkenes toward Different Electrophiles

\begin{tabular}{|c|c|c|c|c|}
\hline & & $\begin{array}{c}\mathrm{Ph}_{2} \mathrm{CH}^{+} \text {- Addition } \\
\mathrm{k}_{\text {rel }}\end{array}$ & $\begin{array}{l}\text { Bromination } \\
k_{2} / 3.72 \cdot 10^{4} \\
\left(\mathrm{~mol}^{-1} \mathrm{sec}^{-1}\right)\end{array}$ & $\begin{array}{l}\text { Hydration } \\
\mathrm{k}_{2} / 3.71 \cdot 10^{-4} \\
\left(\mathrm{~mol}^{-1} \mathrm{sec}^{-1}\right)\end{array}$ \\
\hline$\stackrel{2 a}{\underline{a}}$ & $=$ & $1.8 \cdot 10^{-4}$ & $0.0108(11)$ & $\begin{array}{l}1.33 \cdot 10^{-4}(13) \\
6.42 \cdot 10^{-6}(14)\end{array}$ \\
\hline$\underline{\underline{2 b}}$ & 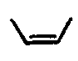 & $3.8 \cdot 10^{-3}$ & $0.640 \quad(11)$ & $2.24 \cdot 10^{-4}(13)$ \\
\hline$\stackrel{2 c}{\underline{c}}$ & & $5.4 \cdot 10^{-3}$ & $0.349 \quad(11)$ & $9.46 \cdot 10^{-5}(13)$ \\
\hline$\stackrel{2 \mathrm{~d}}{=}$ & & 1.0 & $1.00 \quad(11)$ & 1.00 \\
\hline$\underline{2 e}$ & & 1.2 & $1.62 \quad(12)$ & 1.41 \\
\hline$\stackrel{2 f}{=}$ & & 1.16 & $0.976 \quad(11)$ & \\
\hline$\stackrel{2 \mathrm{~g}}{\underline{\mathrm{g}}}$ & & 51 & 34.7 & 0.580 \\
\hline$\underline{2 h}$ & & 27 & 484 & 0.922 \\
\hline$\stackrel{2 i}{=}$ & & $5.6 \cdot 10^{-2}$ & & $9.19 \cdot 10^{-2}(15)$ \\
\hline$\underline{2} \underline{\underline{j}}$ & & 0.43 & 0.0411 (11) & $1.00 \cdot 10^{-3}(13)$ \\
\hline$\underline{2 k}$ & & 2.0 & 0.0868 (11) & $3.02 \cdot 10^{-4}(13)$ \\
\hline 21 & & $6.2 \cdot 10^{-2}$ & $0.0213(11)$ & $3.29 \cdot 10^{-4}(e)$ \\
\hline
\end{tabular}

a) This work; b) $\mathrm{CH}_{3} \mathrm{OH}, 25^{\circ} \mathrm{C}$; c) Acid catalysed hydration in $\mathrm{H}_{2} \mathrm{O}$ at $25^{\circ} \mathrm{C}$; d) From rel. rates of $\underline{2} \underline{g}$ and $\underline{2} \underline{\underline{h}}$ (ref. 16); e) From rel. rates of $\underline{2 k}$ and $\underline{21}$ in $\mathrm{CF}_{3} \mathrm{CO}_{2} \mathrm{H}$ (ref. 17).

Electrophilic additions to alkenes may proceed via bridged or via open transition states. ${ }^{20}$ For halogenations and sulfenylations of alkylethylenes a bridged transition state was suggested, since these reactions are almost equally accelerated by alkyl groups at both alkene termini (Table 1). In contrast, hydration rates are almost unaffected by $\beta$-methyl groups, while they are strongly increased by $\alpha$-methyl groups (Table 1). These findings indicate a transition state resembling a classical carbenium ion, though the large reactivity difference of isobutene and styrene $\left(10^{3} !\right)$ is unexplained.

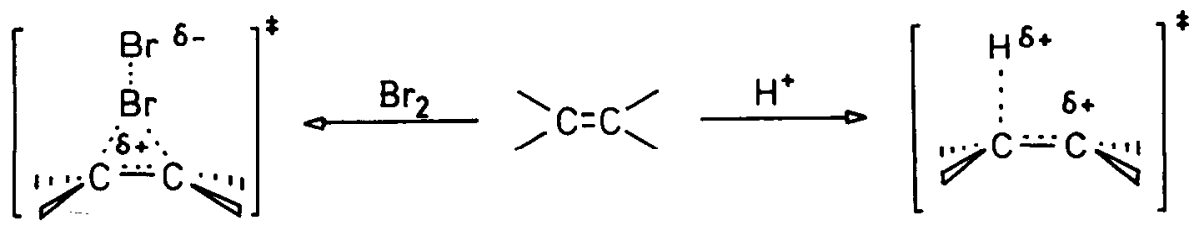

Carbenium ion additions have been postulated to proceed via an open transition state like protonations since in both reactions, alkenes and analogously substituted alkynes show similar reaction rates. ${ }^{20}$ This conclusion was in agreement with the finding ${ }^{2}$ that intro-

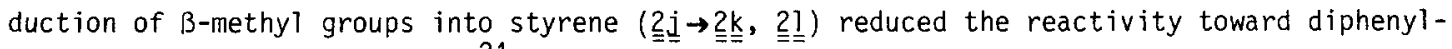
methyl cation (steric effect). ${ }^{21}$ 
Except for 21 , which probably has a nonplanar $\pi$-system, we find that the reactivity toward the diphenylcarbenium ion is increased by methyl groups at the $\beta$-carbon $(\underline{\underline{a}} / \underline{\underline{b}} ; \underline{\underline{d}} / \underline{\underline{g}}$; $\underline{\underline{j}} / \underline{\underline{k}})$. The similar reactivity of $\underline{\underline{2} g}$ and $\underline{\underline{h}} \underline{\underline{h}}$ indicates that the electronic acceleration of the fourth methyl group is compensated by the steric retardation.

These data indicate a transition state which is not solely controlled by the product carbenium ion. If the approach of $\mathrm{Ph}_{2} \mathrm{CH}^{+}$to the alkene resembles that of a proton, the transition state must be located earlier on the reaction coordinate, and the acceleration by B-methyl groups can be due to the reduced HOMO (alkene) - LUMO $\left(\mathrm{Ph}_{2} \mathrm{CH}^{+}\right.$) energy difference (frontier orbital term ${ }^{22}$ ). Alternatively, a partially bridged transition state, where the $\beta-$ carbon (attacked position) of the alkene carries part of the positive charge, is in accord with our results.

We thank Prof.P.V.R. Schleyer and Dr.S.D. Pask for comments, the Deutsche Forschungsgemeinschaft and the Fonds der Chemischen Industrie for financial support.

(1) J.P. Kennedy and E. Maréchal "Carbocationic Polymerization"; Wiley-Interscience, New York 1982.

(2) F. Marcuzzi, G. Melloni and G. Modena, J. Org. Chem. 44, 3022 (1979).

(3) Y. Wang and L.M. Dorfman, Macromolecules 13, 63 (1980).

(4) H. Mayr, Angew. Chem. 93, 202 (1981); Angew. Chem., Int. Ed. Engl. 20, 184 (1981).

(5) H. Mayr and W. Striepe, J. Org. Chem., in press.

(6) H. Mayr and I.K. Halberstadt-Kausch, Chem. Ber. 115, 3479 (1982).

(7) Some of the adducts are described in ref. 5 .

(8) Typical concentrations (mol/1): 1: $0.01, \stackrel{2}{=}: 0.2, \mathrm{ZnCl}_{2}: 0.03, \mathrm{Et}_{2} 0: 0.04$.

(9) Separation on $25 \mathrm{~cm}$ columns packed with NUCLEOSIL 5-NO ${ }_{2}$, NUCLEOSIL 5-C18, or LICHROSORB RP8-10 $\mu \mathrm{m}$, UV detection at $254 \mathrm{~nm}$.

(10) C.K. Ingold and F.R. Shaw, J. Chem. Soc. 1949, 575.

(11) M.F. Ruasse, J.-E. Dubois and A. Argile, J. Org. Chem. 44, 1173 (1979).

(12) E. Bienvenue-Goëtz and J.-E. Dubois, Tetrahedron 34, 2021 (1978).

(13) P. Knittel and T. T. Tidwell, J. Am. Chem. Soc. $\stackrel{99}{=} 3408$ (1977).

(14) K. Oyama and T.T. Tidwe11, J. Am. Chem. Soc. 98, 947 (1976).

(15) W.K. Chwang, V.J. Nowlan, and T.T. Tidwe11, J. Am. Chem. Soc. 99, 7233 (1977).

(16) J.-E. Dubois and G. Mouvier, Bul1. Soc. Chim. France 1968, $142 \overline{6}$.

(17) A.D. Allen, M. Rosenbaum, N.0.L. Seto and T.T. Tidwel1, J. Org. Chem. 47, 4234 (1982).

(18) A. Streitwieser, Jr., Solvolytic Displacement Reactions, McGraw Hil1, New York 1962,p.43.

(19) R. Huisgen, P.H.J. Ooms, M. Mingin, and N.L. Allinger, J. Am. Chem. Soc. 102, 3951 (1980).

(20) G. Melloni, G. Modena and U. Tonellato, Acc. Chem. Res. 14227 (1981).

(21) The discrepancy with our data is not clear; it may be due to a temperature effect:

B. Giese, Angew. Chem. 89, 162 (1977); Angew. Chem., Int. Ed. Engl. 16, 125 (1977).

(22) I. Fleming, Frontier Orbitals and Organic Chemical Reactions, Wiley, New York 1976.

(Received in Germany 23 February 1983) 